\title{
Beden Eğitimi ve Spor Öğretmenliği Bölümü Öğrencilerinin Serbest Zaman Doyum Düzeyi ve Problem Çözme Becerileri Arasındaki İlişkinin İncelenmesi ${ }^{1}$
}

\author{
Erdem ERDEMLİ ${ }^{2}$ ve Fatih YAȘARTÜRK ${ }^{3}$
}

\section{Öz}

$\mathrm{Bu}$ araştırmanın amacı, Bartın ve Kastamonu Üniversitelerinde öğrenim gören Beden Eğitimi Spor ve Öğretmenleri adaylarının serbest zaman faaliyetlerine yönelik doyum düzeyi ile problem çözme becerileri arasındaki ilişkinin incelenmesidir. Araştırmaya Bartın ve Kastamonu Üniversitesi Beden Eğitimi ve Spor Yüksekokulu Beden Eğitimi ve Spor Öğretmenliği Bölümünde öğrenim gören 536 (351 erkek ve 185 kadın) gönüllü öğrenci katılmıştır. Araştırmada veri toplama aracı olarak kişisel bilgi formu, Beard ve Ragheb (1980) tarafindan geliştirilen ve Türkçe uyarlaması Gökçe ve Orhan (2011) tarafindan yapılan "Serbest Zaman Doyum Ölçeği (SZDÖ)" ile Heppner ve Petersen (1982) tarafindan geliştirilen ve Türkçe uyarlama çalışması Şahin, Şahin ve Heppner (1993) tarafindan yapılan "Problem Çözme Envanteri (PÇE)" kullanılmıştır. Verilerin analizinde frekans, yüzde, t-Testi, ANOVA ve Pearson Korelasyon testleri kullanılarak analiz yapılmıştır. Araştırmanın bulguları incelendiğinde, t-Testi sonuçlarında "cinsiyet" değişkenine göre SZDÖ toplam puan ortalamalarında anlamlı farklılık tespit edilirken $(p<0,05)$ PÇE toplam puan ortalamalarında anlamlı farklılık bulunmamıștır ( $\mathrm{p}>0,05)$. Diğer taraftan, ANOVA testi sonuçlarında "yaș" ve "sınıf" değişkenine göre SZDÖ ve PÇE toplam puan ortalamalarında anlamlı farklılık tespit edilmemiştir $(p>0,05)$. Benzer şekilde "gelir düzeyi" değişkenine göre ANOVA testi sonuçlarında SZDÖ ve PÇE toplam puanları arasında anlamlı farklılık tespit edilmemiștir ( $\mathrm{p}>0,05)$. Ayrıca SZDÖ ve PÇE toplam puan ortalamaları arasında anlamlı bir ilişki olmadığı belirlenmiştir $(p>0,05)$. Sonuç olarak, katılımcıların serbest zaman doyum düzeylerinin cinsiyet değișkenine göre farklılık gösterdiği, problem çözme becerilerinde hiçbir değișkende farklılık göstermediği; SZDÖ ve PÇE arasında anlamlı bir ilişki görülmemiştir. Katılımcıların serbest zamanlarını olumlu ve doğru bir şekilde kullanması durumunda karșılaşacağı problemlerle bașa çıkabilecekleri ve problem çözmedeki bașarı düzeylerinin de olumlu şekilde gelişeceği söylenebilir.

Anabtar Kelimeler: Beden eğitimi ve spor öğretmeni, Serbest zaman doyum, Problem çözme

Examination of the Relationship between Free Time Satisfaction Level and Problem Solving Skills of Physical Education and Sports Teacher Department Students

\begin{abstract}
The aim of this study was to investigate the relationship between the level of satisfaction and problem solving skills for leisure time activities of physical education sports and teacher candidates who are studying at Bartın and Kastamonu universities. The study included 536 (351 male and 185 female) volunteer students who are educated in the Department of Physical Education and sports teaching of Bartın and Kastamonu University School of Physical Education and Sports. As a data collection tool, the personal data Form prepared by the researcher was developed by Beard and Ragheb (1980) and the Turkish adaptation by Gokce and Orhan (2011) "Leisure Satisfaction Scale (LSS)", Heppner and Petersen (1982) and the Turkish adaptation by Sahin et al. (1993) the "Problem Solving Inventory (PSI)" was used. The data were analyzed using frequency, percent, t-test, ANOVA and Pearson correlation tests. When the findings of the study were examined, there was no significant difference in the mean scores of LSS according to the "gender" variable $(\mathrm{p}>0,05)$ in the T-test results $(\mathrm{p}>0.05)$. On the other hand, there was no significant difference in the mean scores of LSS and PSI according to the "age" and "class" variables in the ANOVA test results ( $\mathrm{p}>0.05)$. Similarly, according to the "income level" variable, there was no significant difference between LSS and PSI total scores in the ANOVA test results $(p>0.05)$. Finally, it was found that there was no significant correlation between the mean scores of LSS and PSI ( $p>0.05$ ). As a result, there was no significant correlation between LSS and PSI in the problem solving skills, where the free time saturation levels of the participants varied according to gender variables and there was no significant correlation between LSS and PSI. It can be said that if participants use their free time in a positive and correct way, they can deal with the problems they will face and their success levels in problem solving will increase in a positive way.
\end{abstract}

Key Words: Physical education and sports teacher, Free time, Problem solving

\section{Atıf İçin / Please Cite As:}

Erdemli, E. ve Yaşartürk F. (2020). Beden eğitimi ve spor öğretmenliği bölümü öğrencilerinin serbest zaman doyum düzeyi ve problem çözme becerileri arasındaki ilişkinin incelenmesi. Manas Sosyal Araştırmalar Dergisi, 9(3), 1871-1882.

Geliş Tarihi / Received Date: 16.08.2019

Kabul Tarihi / Accepted Date: 11.06.2020

\footnotetext{
${ }^{1}$ Bu çalışma 2. Uluslararası Herkes İçin Spor ve Wellness Kongresinde sözel bildiri olarak sunulmuştur.

2 Yüksek Lisans Öğrencisi - Bartın Üniversitesi Eğitim Bilimleri Enstitüsü, erdemli.erdem37@gmail.com ORCID: 0000-0002-5069-1650

${ }^{3}$ Doç. Dr. - Bartın Üniversitesi Spor Bilimleri Fakültesi, fatihyasarturk@gmail.com - ORCID: 0000-0003-4934-101X
} 


\section{Giriş}

Günlük hayatın zorlukları problemleri stresleri yoğun iş yaşantısı gibi durumlarda bireyin kendini yenilemek, geliştirmek, yaşamını zenginleştirmek ve yaşam kalitesini arttırmak için kendisine bir zaman ayırması gerekmektedir. İnsanlar bu gibi durumlardan kendilerine vakit ayıramadıkları zamanlarda depresyon, iş hayatlarında verimsizlik, mutsuzluk ve stres artışı gibi sorunlarla karşılaşabilmektedirler. Birey kendisine ayırdığı zamanı kendi yaptığ1 tercihlerle özgür bir şekilde değerlendirir. Bireyin yaptığ1 bu tercihlerle birlikte serbest zaman bütünleşmiş olur. Yapılan birçok araştırmada serbest zamanda yapılan aktivitelerin olumlu bir şekilde yararlı olduğu gözlenmiştir.

Serbest zamanın açıklamaları yapılan çalışmalarda en fazla tekrarlanan konu, kişilerin yaşamları dışında yer bulan sürelerin vurgulanmasıdır. Bu süreden kastedilen şey ise, öncelik olarak bireylerin tercihlerine dayanması, kişide memnuniyet yaşatması ile eğlenceye yönelik bir yaşam doyumu oluşturmasıdır (Pearson, 2008). Söz konusu doyum, aile ile arkadaşları içinde bulunduran sosyal birliktelik kazanmış bir şekilde artmaktadır. Yani birçok çalışmada aile ile yapılan serbest zamanların, bireyin sosyal hayatına pozitif etkileri olduğu söz konusudur (Agate vd., 2009). Yaşamın gerçek kısmı, serbest zaman ile geçmektedir ayrıca kişinin boş vakitlerindeki meşguliyetleri, aynı şekilde kişinin gelişmesinde sağlam adım olarak değerlendirilmektedir bununla birlikte gelecek hayatında ne şekilde birey haline geleceğini de etkilemektedir. Serbest vaktin ne şekilde harcanıldığı, buna benzer zaman şeklinde kişisel alaka ile amaçların güven verecek biçimde ölçüt olarak görülmektedir. Vakti, çalışma yaşamının bağlılı̆̆ ile başka sosyal çatışmalardan uzak bir şekilde, etkili bir biçimde kullanmanın binlerce yolu bulunmaktadır bununla birlikte herhangi seçenek üzerinden tercihinin olması gerekmektedir (Sivan ve Ruskin, 2000). Serbest zaman doyumu, bireyin serbest zamanlarındaki uğraşlarını algılaması ya da kişisel olumlu duyguları üzerine kurulmuş ve kişilerin serbest zaman aktivitelerine katılarak kişisel gereksinimlerini karşılamaları sonucunda kazandıkları pozitif duygular olarak ifade edilmektedir (Du Cap, 2002; Seigenthaler, 1997).

Neugarten vd. (1961) doyum kavramını, kişinin özü ayrıca hayatıyla birlikte olmasını diledikleriyle olan şeylerin karşılaştırılmasıyla olan durum veya sonuç olarak aktarılmaktadır (Özer ve Karabulut, 2003). Mutluluk kavramı, moral ve benzeri gibi birçok açlardan iyi olma durumunu ifade etmektedir (Quintina ve Vera, 1999). Kişinin yaşam doyumu algılaması, hayatı hakkında değer biçmesiyle kendisine yüklediği subjektif yargılarla ifade edilir (Pavot ve Diener, 1993). Hayat tatmini, bireyin, iş, serbest zaman ile birlikte diğer zaman bölümlerindeki hayatına gösterdiği duygusal tepki ya da tutumlara denir (Köker, 1991). Başka bir deyişle genel hatlarıyla hayat tatmini, bireyin, çalışma, serbest vakit ile başka iş dışındaki vakit şeklinde ifade veren, hayata karşı hissi reaksiyonu şeklinde adlandırılmıştır (Keser, 2005). Hayat tatmini tarifindeki tatmin tanımı; umut, ihtiyaç, talep ile düşlerin sağlanmasını tanımlar. Hayat tatmini temel anlamıyla kişinin hayatını kapsamaktadır (Avşaroğlu vd., 1999). Kişilerin yaşam doyumuna varabilmesi, bireyin kişisel farklılıklarından kaynaklanan bir durumdur. Örnek olarak; müzik dinlemek, kitap okumak, sinemaya gitmek, resim yapmak, tiyatro izlemek, sportif etkinliklere katılmak gibi bu zaman diliminin içerisinde yapılan gönüllü katılım olarak yapılan serbest zaman aktiviteleridir. Bu süreçte geleceğin teminatı olan gençliğin lisans eğitimi içinde serbest zamanlarını olumlu yönde, yaşam doyumlarını etkileyecek bir şekilde geçirmesi için olanakların sunulması gerekir veya mevcut oluşan durumların tespiti gerekir ki eksik kalan yönleri var ise doldurulmak üzere çalışmalar yapılsın (Kalfa, 2017).

Geçmişten günümüze kadar dünya üzerinde yaşayan insanlar birçok problemlerle karşı karşıya kalmışlardır. Tarihin en eski yıllarından itibaren temel ihtiyaçlarla birlikte günümüze kadar gelen birçok problemi çözmeye onlarla başa çıkmaya çalışmıslardır. Hedeflenen sonuçların alınmasını engelleyen aksatan, çözümlenmesi gerekmekte olup çözülemeyen birçok problemle insanoğlu baş başa kalmıştır. İnsanlar, problemin durumuna göre çözüm yolları aramaya ve bu çözüm yollarını bulup geliştirmeye çalışmışlardır. Tüm alanlarda olduğu gibi spor dünyasında da birçok sporcu antrenör öğrenci spor bilimci gibi sporla uğraşan insanlar da birçok problemlerle karşı karşıya kalmıştır. Diğer taraftan da bu problemleri değerlendirip farklı çözüm yolları aramışlardır.

Problem çözme, hedefe varmakla gerçekleşen zorlukları kazanma durumu şeklinde ifade edilmektedir. Gösterilen durum, şartlara uyarak ya da engelleri en aza indirgeyerek gergin durumdan kurtulma ile organizmanın iç dengeyle birlikte olmasının yöntemlerini bulmaya çalışır. Problem çözme, öğrenilmesi ya da elde edilmesi gereken bir yetenektir bununla birlikte devamlı olarak geliştirilmesi gereklidir (Bingham, 1998). Kişi karşılaştı̆̆ zorluk ile çözmesi gerekli olan bir durum içerisinde hâkim olduğu bütün kaynakları harekete geçirmekte, problemin çözülebilmesine yönelik ipuçları ile farklı fikirler elde etmek durumuyla önceden edindiği bilgileri gözden geçirmelidir. Kişinin problem çözmedeki başarısı, problem çözmesine bağlı olarak gelişen bir durumdur (Ağır, 2007). Problem çözme becerisi, hayatın tamamında etkin 
düşünülen ayrıca yalından komplike şeklinde tüm durumlarda gerçekleşen mühim hayat becerisi olmuştur. Kişi, galip geldiği sorunu bitirme beceresi ile sağladığı yakın veya uzak durumlarla yaşamına pozitif veya negatif yön verebilmektedir (Gülşen, 2008).

Kişilerin karşı karşıya kaldıkları problemlerin bazıları, sade işlem ile eylemlerle, bazıları ise oldukça yoğun bir düşünmeyle bazıları da sahip oldukları yetenekler ile çözülebilmektedir (Gülşen, 2008). Sporcular içinde bu durumun muteber şeklinde gerçekleştĭgini söyleyebiliriz. Kişilerin sahip olduğu düzeyde değerler ile tutumlar, düşünce tarzı ayrıca uygulanan tutumlar ve problemleri çözmede ciddi şekilde değerlendirilmektedir. Alanda veya alana benzer yerlerde kişi öz pozisyonu ile gerçekleştireceği konumu, rakibinin durumuna bakarak aynı zamanda birlikte oldukları durum ile konumuna bakarak değerlendirebilmelidir (Karabulut, 2009). Sporcu bireyler, herhangi bir problem ile karşı karşıya kaldıklarında, deneyimlerinin dışında gerçekleşen sorunları farklı şekilde halletmeye çalışırlar. Sorun halletme düşüncesiyle kişi, kendi kapasitesi ile hedefine doğru yönde gidip sorunu çözmede başarllı bir tutum sergilemiştir (Baumann, 1994).

Hayatımızdaki sorunlar tüm kişilerin aynı değerlendirilmesi ile birlikte, spor ile uğraş veren kişilerin, uğraştıkları spor dalı, kulüp ile yönetici gibi farklı stres faktörü oluşturan problemlerle karşılaştıkları düşünüldügünde, sedanter kişilerden göre daha çok sorunla karşılaştıkları söylenmektedir. Sedanter olmayan kişilerin, sedanter bireylere nazaran sorunla baş başa kaldıklarında fazla elastik ayrıca iyi görüldükleri söylenmektedir. Zor olan durumlarda kendine inanan, katlanan, kişi ile durumlant güzel olan, önder vasıflı, düzenli yani öz olarak sağlam birey türlerine hâkim insanlar kalmaktadır (Barut ve Yılmaz, 2000). Beden eğitimi ve spor öğretmeni adayların serbest zamanlarını değerlendirdikleri durumlarda kendini yenilemeli, kendini geliştirmeleri, yaşamlarını zenginleştirmeli, yaşam kalitesini arttırmalı, mutlu olmalı ve stres olabilecek durumlardan kaçınmalıdır. Serbest zamanlarını bu şekilde iyi değerlendiren öğretmen adayları böylelikle meslekleriyle ilgili problemlerinde sağlam adımlar atıp problemi çözme yolunda başarı elde edeceklerdir. İyi bir şekilde değerlendirilip kullanılan serbest zamanın problem çözme becerilerine olan etkisinde serbest zaman; bireylerin zihinsel ve fiziksel gelişimine katkıda bulunur, stres ve kaygıyı azaltır, kişisel yetenek ve becerilerini kullanma fırsatını arttırır, yaratıcı olmalarını sağlar, kendini ifade edebilme yeteneğinin gelişimine yardımcı olur, bireylerin potansiyelleri ve disiplinli olma anlayışını güçlendirir. Bu cümleler doğrultusunda bireyler günlük hayatlarında karşılaştıkları problemlerle etkili bir şekilde çözüm yoluna ulaşacaklar ve başarılı bir şekilde karşılarına çıkan problemleri çözebileceklerdir.

Araştırmadaki bilgiler doğrultusunda bu araştırmanın problem cümlesi beden eğitimi ve spor öğretmeni adaylarının serbest zaman doyum ile problem çözme becerileri arasındaki ilişkinin incelenmesidir.

Araştırmanın alt problemleri ise:

1. Beden eğitimi ve spor öğretmeni adaylarının bazı demografik değişkenlere göre serbest zaman doyum düzeyleri arasında anlamlı bir farklilık var mıdır?

2. Beden eğitimi ve spor öğretmeni adaylarının bazı demografik değişkenlere göre problem çözme düzeyleri arasında anlamlı bir farklilık var midır?

3. Beden eğitimi ve spor öğretmeni adaylarının serbest zaman doyum düzeyleri ile problem çözme becerileri arasında anlamlı bir ilişki var mıdır?

Araştırmanın hipotezleri ise:

1. Beden eğitimi ve spor öğretmeni adaylarının bazı demografik değişkenlere göre serbest zaman doyum düzeyleri arasında anlamlı bir farkllık vardır.

2. Beden eğitimi ve spor öğretmeni adaylarının bazı demografik değişkenlere göre problem çözme düzeyleri arasında anlamlı bir farklılık vardır.

3. Beden eğitimi ve spor öğretmeni adaylarının serbest zaman doyum düzeyleri ile problem çözme becerileri arasında anlamlı bir ilişki vardır. 


\section{Yöntem}

Bu araştırma, Bartın Üniversitesi Sosyal ve Beşeri Bilimleri Etik Kurulu’na gönderilmiş etik kurul onay belgesi alınmıştır.

\section{Araştırmanın Modeli}

Araştırma modeli olarak "betimsel ve ilişkisel tarama modeli" kullanılmıştır. Betimsel tarama modelleri, çok sayıda elemanlardan oluşan bir evrende, evren hakkında genel bir yargiya varmak amaciyla evrenin tümü ya da ondan alınacak bir grup örnek ya da örneklem üzerinde yapılan tarama düzenlemeleri olarak tanımlanmaktadır. İlişkisel tarama modelleri ise; iki ve daha çok sayıdaki değişken arasında birlikte değişim varlığını ve derecesini belirlemeyi amaçlayan araştırma modelleridir (Karasar, 2017).

\section{Evren ve Örneklem}

Araştırmanın evreni 2018-2019 döneminde Bartın ve Kastamonu Üniversitelerinde öğrenim gören beden eğitimi ve spor öğretmenliği bölümü öğrencileridir. Çalışmanın örneklemi ise Bartın ve Kastamonu Üniversitesi beden eğitimi ve spor öğretmenliği bölümünde okuyan 536 (351 erkek ve 185 kadın) öğrencilerden oluşmaktadır.

\section{Veri Toplama Araçları}

Araştırmada veri toplama aracı olarak araştırmacılar tarafindan geliştirilen kişisel bilgi formu kullanılmıştır. Kişisel bilgi formunda katılımcılara yönelik cinsiyet, yaş, sınıf ve gelir düzeyine yönelik sorular yer almaktadır.

Serbest Zaman Doyum Ölçeği (Leisure Satisfaction Scale/LSS) Beard ve Ragheb (1980) tarafindan geliştirilen Gökçe ve Orhan (2011) tarafindan Türkçeye uyarlanmıştır. SZDÖ toplam 24 madde ve Psikolojik, Eğitimsel, Sosyal, Fiziksel, Rahatlama ve Estetik olmak üzere altı alt boyuttan oluşmaktadır. SZDÖ 5'li likert tipi yapısından oluşmakta ve "Neredeyse hiç doğru değill, "Nadiren doğru", "Bazen doğru", "Çoğu kez doğru", "Neredeyse her zaman doğru" ifadelerine göre 1 ile 5 arasinda puanlandırılmışır. Ölçeğin uyarlama çalışmasında alt boyutlara ilişkin hesaplanan iç tutarlık kat sayıları sırasıyla $0,77,0,77,0,76,0,80,0,79$ ve 0,79 olarak bulunmuştur. Bu araştırmada toplanan veriler üzerinden ölçeğin alt boyutları için hesaplanan iç tutarlılık kat sayıları alt boyutlara göre "Psikolojik, 0,74", "Eğitimsel, 0,80", "Sosyal, 0,79", "Rahatlama, 0,78”, "Fiziksel, 0,80" ve "Estetik, 0,73" olarak bulunmuştur. Ölçeği oluşturan tüm alt faktörlerin sınıflama geçerliğin analizi için yapılan bağımsız grup testi sonuçlarında tüm faktörlerde alt üst grup arasında $\mathrm{p}<0.001$ düzeyinde anlamlı farklılaşma tespit edilmiştir.

Problem Çözme Envanteri (Problem Solving Inventory/PSI) Heppner ve Petersen (1982) tarafindan bireylerin problemlerini çözebilme yeterliği konusunda kendilerini nasıl algıladıklarını ve problem çözmenin boyutlarını belirlemek amacıyla problem çözmenin genel yönelim, problemin tanımı, alternatif üretme, karar verme ve değerlendirme aşamaları göz önünde bulundurularak geliştirilmiştir. Türkçe uyarlama çalışması Şahin, Şahin ve Heppner (1993) tarafindan yapilmıştır. Problem Çözme Envanteri, 6’lı likert tipi ve 35 maddeden oluşmaktadır. İfadelerin karşısında "Her zaman böyle davranırım-(1), Çoğunlukla böyle davranırım-(2), S1k sık böyle davranırım-(3), Arada sırada böyle davranırım-(4), Ender olarak böyle davranırım-(5) ve Hiçbir zaman böyle davranmam-(6)" seçenekleri yer almaktadır. Puanlama 9,22 ve 29. maddeler puanlama dışı birakılarak 32 madde üzerinden yapılır. 1, 2, 3, 4, 11, 13, 14, 15, 17, 21, 25, 26, 30 ve 34. Maddeler ters olarak puanlanır. Envanterden alınabilecek puan aralığı 32-192 arasıdır. Puanlamada düşük puanlar problemleri çözmede etkililiği, yüksek puanlar problemler karşısında etkili çözümler bulamamayı gösterir (Taylan, 1990). PÇE alt boyutları ise aceleci yaklaşım, düşünen yaklaşım, kaçıngan yaklaşım, değerlendirici yaklaşım, kendine güvenli yaklaşım ve planlı yaklaşım olmak üzere altı faktörden oluşmakta ve iç tutarlık kat sayıları sırasıyla $0,78,0,76,0,74,0,69,0,64$ ve 0,59 olarak tespit edilmiştir. Bu araştırmada kullanılan ölçek için hesaplanan iç tutarlılık kat sayıları alt boyutlara göre sırasıyla $0,74,0,79,0,73,0,65,0,64$ ve 0,61 olarak tespit edilmiştir. Ölçekten alınan düşük puanlar, bireyin kendini problem çözmede özgüvenli, problemlerin çözümü konusunda daha çok kişisel kontrole ve sorunlara yaklaşabilme eğilimine sahip olarak algıladığını göstermektedir (Savaşır ve Şahin, 1997).

\section{Verilerin Analizi}

Verilerin analizinde; verilerin normalliği gözetilerek katılımcıların demografik özelliklerine göre, serbest zaman doyum düzeyleri ve problem çözme becerileri arasındaki farkl1lıkları incelemek amaciyla tTesti ve ANOVA; değişkenler arasındaki ilişkilerin incelenmesi için ise Pearson Korelasyon testi uygulanmıştır. Araştırma çerçevesinde ölçeklere verilen yanıtların aritmetik ortalamaları $(\bar{X})$ standart sapmaları 
(ss) hesaplanarak kattlımcıların serbest zaman doyum ölçeği ile problem çözme becerileri ölçeği düzeylerine ilişkin dağılımlar belirlenmiştir ve ölçme aracının güvenirliliğini test etmek için Cronbach Alpha iç tutarlılık katsayısı hesaplanmıştır.

\section{Bulgular}

Bu bölümde çalısmaya yönelik tablolara ve yorumlara yönelik bilgiler yer almaktadır.

Tablo 1. Katılimcularm demografik değişskenlere göre tammlaync istatistik sonuclar

\begin{tabular}{|c|c|c|c|c|c|}
\hline \multicolumn{2}{|c|}{ Değişkenler } & $\boldsymbol{N}$ & $\%$ & $\bar{x}$ & $s$ \\
\hline \multicolumn{2}{|l|}{ Yaş } & 536 & & 21.15 & 2.66 \\
\hline \multicolumn{2}{|c|}{ Gelir Düzeyi } & 536 & & 3178.85 & 2284.38 \\
\hline \multirow{2}{*}{ Cinsiyet } & Kadın & 185 & 34.5 & & \\
\hline & Erkek & 351 & 65.5 & & \\
\hline \multirow{4}{*}{ Sinif } & 1. Sinif & 152 & 28.4 & & \\
\hline & 2.Sinif & 130 & 24.3 & & \\
\hline & 3.Sinif & 122 & 22.8 & & \\
\hline & 4.Sinif & 132 & 24.6 & & \\
\hline
\end{tabular}

Katılımcıların yaş ortalamaları 21,15; gelir düzeyleri ise aylık olarak 3178,85 TL olarak belirlenmiştir. Katılımcıların yüzde \%34,5’ini kadın, \%65,5’ini erkek öğrenciler olușturmaktadır. Öğrencilerin \%28,4'ü 1. sinıf, 24,3’ü 2. sinıf, 22,8’i 3. sinıf ve 24,6's1 4.sinıfta eğitim görmektedir.

Tablo 2. Katzlimollarn Cinsiyet Deģ̆işkenine Göre PÇE ve SZDÖ t-Testi Sonuclar

\begin{tabular}{|c|c|c|c|c|c|c|}
\hline & & $\begin{array}{c}\text { Kadın } \\
(\mathrm{N}=185) \\
\end{array}$ & & $\begin{array}{c}\text { Erkek } \\
(\mathrm{N}=351) \\
\end{array}$ & & \\
\hline & $\bar{x}$ & Ss & $\bar{x}$ & Ss & $\mathrm{t}$ & $\mathbf{P}$ \\
\hline$\overline{\text { Aceleci }}$ & 33,60 & 7,46 & 32,56 & 7,72 & ,011 & ,135 \\
\hline Düşünen & 13,98 & 5,22 & 14,18 & 5,06 &, 451 & 661 \\
\hline Kaçıngan & 16,87 & 5,20 & 15,93 & 5,21 & ,154 &, $047 *$ \\
\hline Değerlendirici & 8,15 & 3,63 & 8,70 & 3,50 & ,483 & ,084 \\
\hline Kendine Güvenli & 17,74 & 5,25 & 17,75 & 5,39 &, 177 &, 976 \\
\hline Planlı Yaklaşım & 10,70 & 4,39 & 10,99 & 4,18 &, 524 &, 456 \\
\hline PÇE Toplam & 114,37 & 20,92 & 113,07 & 22,52 & ,249 &, 515 \\
\hline Psikolojik & 14,33 & 3,91 & 13,72 & 3,87 &, 042 & 087 \\
\hline Eğitimsel & 15,47 & 3,40 & 14,36 & 3,73 & 2,458 &, $001 *$ \\
\hline Sosyal & 14,99 & 3,57 & 14,37 & 3,80 & 2,701 & 069 \\
\hline Fiziksel & 15,63 & 3,73 & 14,85 & 3,70 & ,011 &, $022 *$ \\
\hline Rahatlama & 14,28 & 3,23 & 13,85 & 3,69 & 5,302 & ,186 \\
\hline Estetik & 14,93 & 3,42 & 14,22 & 3,61 & ,184 &, $029 *$ \\
\hline SZDÖ Toplam & 89,65 & 16,59 & 85,41 & 18,61 & 4,117 &, $010 *$ \\
\hline
\end{tabular}

Tabloya göre katılımciların PÇE toplam puan ortalamaları ve alt boyutları, SZDÖ toplam puan ortalamaları ve alt boyutları cinsiyet değişkeni açısından incelendiğinde PÇE "Kaçıngan" alt boyutunda istatistiksel olarak anlamlı bir farklılık tespit edilmiştir $(p<0,05)$. SZDÖ toplam puan ortalamaları ve alt boyutları cinsiyet değişkeni açısından incelendiğinde SZDÖ toplam puan ortalamalarında ve "Eğitimsel, Fiziksel ve Estetik" alt boyutlarında istatistiksel olarak anlamlı bir farklılık tespit edilmiştir $(p<0,05)$. 
Beden Eğitimi ve Spor Öğretmenliği Bölümü Öğrencilerinin Serbest Zaman Doyum Düzeyi ve Problem Çözme Becerileri Arasındaki İlişkinin İncelenmesi

Tablo 3. Kattlimolarn Yas Değişkenine Göre PÇE ANOV A testi Sonuclar

\begin{tabular}{lccc}
\hline \multicolumn{1}{c}{ Alt Boyutlar } & $\mathbf{f}$ & $\mathbf{p}$ & Anlamli Fark \\
\hline Aceleci & 2,145 &, 094 & - \\
Düşünen & 3,529 & $\mathbf{0 1 5 *}$ & $\mathbf{1 - 3 , 3 - 4}$ \\
Kaçingan & 1,836 &, 140 & - \\
Değerlendirici & 4,133 & $\mathbf{0 0 7 *}$ & $\mathbf{2 - 4 , \mathbf { 3 }}$ \\
Kendine Güvenli & 2,555 &, 055 & - \\
Planlı Yaklaşım & 2,829 & $\mathbf{0 3 8 *}$ & $\mathbf{3 - 4}$ \\
PÇE Toplam & 2,245 &, 082 & $\mathbf{-}$ \\
\hline
\end{tabular}

${ }^{*} \mathrm{p}<.05 * 1$ (18-21 yaş), 2(22-25 yaş), 3(26-29 yaş), 4(30+ yaş)

Tabloya göre katılımcıların PÇE toplam puan ortalamaları ve alt boyutları yaş değişkeni açısından incelendiğinde PÇE "Düşünen, Değerlendirici ve Planlı Yaklaşım" alt boyutlarında istatistiksel olarak anlamlı bir farklılık tespit edilmiştir ( $\mathrm{p}<0,05)$. "Düşünen" alt boyutundaki anlamlı farklılık 18-21 yaş ile 2629 yaş, 26-29 yaş işe 30 üstü yaş gruplarında olduğu ve 26-29 yaş gruplarının lehine olduğu görülmektedir. "Değerlendirici" alt boyutundaki anlamlı farklılık 22-25 yaş ile 30 yaş üstü arasında ve 22-25 yaş gruplarının lehine, ayrıca 26-29 yaş ile 30 yaş üstü arasında 26-29 yaş gruplarının lehine olduğu görülmüştür. "Planlı Yaklaşım" alt boyutundaki anlamlı farklılık ise 26-29 yaş ile 30 yaş üstü arasında olduğu ve 26-29 yaş gruplarının lehine olduğu görülmüştür.

Tablo 4. Katılımcılarn Yaş Değı̧skenine Göre SZDÖ ANOV A testi Sonuçlar

\begin{tabular}{lccc}
\hline \multicolumn{1}{c}{ Alt Boyutlar } & f & p & Anlaml Fark \\
\hline Psikolojik & 1,667 &, 173 & - \\
Eğitimsel & 2,084 &, 101 & - \\
Sosyal & 1,190 &, 313 & - \\
Fiziksel & 1,504 &, 212 & - \\
Rahatlama &, 832 &, 477 & - \\
Estetik &, 496 &, 685 & - \\
SZDÖ Toplam & 1,668 &, 173 & - \\
\hline$*$ p<.05 *1(18-21 yaş), 2(22-25 yaş), 3(26-29 yaş), 4(30+ yaş) & &
\end{tabular}

Tabloya göre katılımcıların SZDÖ toplam puan ortalamaları ve alt boyutları sınıf değişkeni açısından incelendiğinde anlamlı farkllılı tespit edilmemiştir $(\mathrm{p}>0,05)$.

Tablo 5. Katılimcularn Sime Değğskenine Göre PCE ANOV A testi Sonuclar

\begin{tabular}{lccc}
\hline \multicolumn{1}{c}{ Alt Boyutlar } & $\mathbf{t}$ & $\mathbf{p}$ & Anlaml Fark \\
\hline Aceleci &, 679 &, 565 & - \\
Düşünen & 2,100 &, 099 & - \\
Kaçingan & 2,158 &, 092 & - \\
Değerlendirici & 3,251 & $\mathbf{0 2 2}$ & $\mathbf{2 - 4}$ \\
Kendine Güvenli & 4,042 & $\mathbf{0 0 7 *}$ & $\mathbf{1 - 2 , 2 - 4}$ \\
Planlı Yaklaşım &, 947 &, 418 & - \\
PÇE Toplam & 2,052 &, 106 & - \\
\hline$*$ p $<.05$ & & &
\end{tabular}

Tabloya göre katıllımcıların PÇE toplam puan ortalamaları ve alt boyutları sınıf değişkeni açısından incelendiğinde PÇE "Değerlendirici ve Kendine Güvenli" alt boyutlarında istatistiksel olarak anlamlı bir farklılık tespit edilmiştir $(p<0,05)$. "Değerlendirici" alt boyutundaki anlamlı farklılık 2. sınıf ile 4. sınıf arasında 2. sınıfların lehine olduğu görülmüştür. "Kendine Güvenli” anlamlı farklılı̆̆ın 1. ve 2. ve 2. ve 4. sınıf arasında olduğu ve bu farklılı̆ı̆n 4. sınıf öğrencilerinin lehine olduğu tespit edilmiştir.

Tablo 6. Katıllmcılarn Sinf Değişkenine Göre SZDÖ ANOV A testi Sonuclarn

\begin{tabular}{lccc}
\hline \multicolumn{1}{c}{ Alt Boyutlar } & f & p & Anlamli Fark \\
\hline Psikolojik &, 796 &, 497 & - \\
Eğitimsel &, 436 &, 727 & - \\
Sosyal &, 494 &, 687 & - \\
Fiziksel &, 870 &, 457 & - \\
Rahatlama & 2,966 & $\mathbf{0 3 2 *}$ & $\mathbf{2 - 3}$ \\
Estetik & 1,895 &, 129 & - \\
SZDÖ Toplam & 1,414 &, 238 & - \\
\hline
\end{tabular}


Tabloya göre katılımcıların SZDÖ toplam puan ortalamaları ve alt boyutları sınıf değişkeni açısından incelendiğinde SZDÖ "Rahatlama" alt boyutunda istatistiksel olarak anlamlı bir farklilik tespit edilmiştir $(\mathrm{p}<0,05)$. "Rahatlama" alt boyutundaki anlamlı farklılı̆̆ı 2. ve 3. Sinıflar arasında olduğu ve bu farklılığın 2. sinıf öğrencilerinin lehine olduğu tespit edilmiştir.

Tablo 7. Katılimcularn Gelir Düzeyi Değgşseenine Göre PÇE ANOVA testi Sonuçlar

\begin{tabular}{lccc}
\hline \multicolumn{1}{c}{ Alt Boyutlar } & $\mathbf{f}$ & $\mathbf{p}$ & Anlaml Fark \\
\hline Aceleci & 1,250 &, 284 & - \\
Düşünen &, 874 &, 498 & - \\
Kaçingan & 1,104 &, 357 & - \\
Değerlendirici & 1,043 &, 392 & - \\
Kendine Güvenli & 1,223 &, 297 & - \\
Planlı Yaklaşım &, 639 &, 670 & - \\
Problem Çözme Top. & 1,850 &, 102 & - \\
\hline$*$ p $<.05$ & & &
\end{tabular}

Tabloya göre katılımcıların PÇE toplam puan ortalamaları ve alt boyutları gelir düzeyi değişkeni açısından incelendiğinde anlamlı farklılık tespit edilmemiştir ( $\mathrm{p}>0,05)$.

Tablo 8. Katılimcılarn Gelir Düzeyi Değiskenine Göre SZDÖ ANOV A testi Sonuçlar

\begin{tabular}{lccc}
\hline \multicolumn{1}{c}{ Alt Boyutlar } & f & p & Anlaml Fark \\
\hline Psikolojik & 1,582 &, 163 & - \\
Eğitimsel & 1,320 &, 254 & - \\
Sosyal & 1,356 &, 240 & - \\
Fiziksel & 2,538 &, $\mathbf{0 2 8}$ & $\mathbf{2 - 3}$ \\
Rahatlama & 1,010 &, 411 & - \\
Estetik &, 403 &, 847 & - \\
Serbest Zaman Top. & 1,371 &, 234 & - \\
\hline$*$ p $<.05 * 1(0-1000), 2(1001-2000), 3(2001-3000), 4(3001-4000), 5(4001-5000), 6(5001+)$ &
\end{tabular}

Tabloya göre katılımcıların SZDÖ toplam puan ortalamaları ve alt boyutları sınıf değişkeni açısından incelendiğinde SZDÖ "Fiziksel" alt boyutunda istatistiksel olarak anlamlı bir farklllık tespit edilmiştir $(\mathrm{p}<0,05)$. "Fiziksel" alt boyutundaki anlamlı farklılı̆̆ın 1001-2000 TL ile 2001-3000 TL arasında olduğu 1001-2000 TL gruplarının lehine olduğu tespit edilmiştir.

Tablo 9. Katılimcılarn PÇE ve SZDÖ Korelasyon testi sonuclar

\begin{tabular}{cccc}
\hline & & Serbest Zaman Doyum Ölçeği & Problem Çözme Envanteri \\
\hline \multirow{2}{*}{ SZDÖ } & $\mathrm{r}$ & 1 & \\
& $\mathrm{p}$ & 535 & 1 \\
& $\mathrm{n}$ &, 069 & 535 \\
\hline \multirow{2}{*}{ PÇE } & $\mathrm{r}$ &, 112 & 535 \\
& $\mathrm{p}$ & 535 & \\
& $\mathrm{n}$ & & \\
& &
\end{tabular}

Tabloya göre "PÇE ve SZDÖ toplam puan ortalamaları" arasındaki ilişkiyi göstermek amacıyla yapılan pearson korelasyon analizi sonucu verilmiştir. Analiz sonuçlarına göre PÇE ve SZDÖ arasında bir ilişki tespit edilmemiştir ( $\mathrm{p}>0,05)$.

\section{Tartışma, Sonuç ve Öneriler}

Bu çalışmanın amacı, araştırmanın amacı, beden eğitimi ve spor öğretmeni adaylarının serbest zaman doyum ile problem çözme becerileri arasındaki ilişkinin incelenmesidir.

Cinsiyet değişkenine göre, PÇE toplam puan ortalamaları incelendiğinde anlamlı farklılık tespit edilmemiştir. PÇE alt boyutları incelendiğinde ise $(\mathrm{p}>0,05)$ "Kaçıngan" alt boyutunda istatistiksel olarak anlamlı bir farklılık bulunmuştur $(\mathrm{p}<0,05)$. Ortalama değerler incelendiğinde bu anlamlı farklılığın kadın öğrencilerin lehine olduğu görülmektedir. SZDÖ toplam puan ortalamaları ve "Eğitimsel, Fiziksel ve Estetik" alt boyutlarında anlamlı bir farklılık bulunmuştur $(\mathrm{p}<0,05)$. Ortalama değerler incelendiğinde bu anlamlı farklılığın kadın öğrencilerin lehine olduğu görülmektedir. Bu duruma göre kadınların yaşamdan aldıkları doyum, erkek katılımcılardan daha fazla olduğu söyleyebiliriz. Dolayısıyla yaşamdan aldıkları doyum eğitimsel, fiziksel ve estetik açıdan daha memnun olduklarını söyleyebiliriz. Ancak Görücü ve 
Cantav (2017) çalısmasında, algılanan problem çözme becerilerinde erkeklerin lehine göre anlamlı bir fark olduğunu bulmuşlardır. Karabulut (2009) çalışmasında ise, iki farklı üniversitenin öğrencilerinden iki ayrı örneklem grubunu incelemiş ve sonuç olarak ilk grupta erkeklerin problem çözme hususunda değerlendirici yaklaşımın anlamlı bir şekilde daha yüksek, ikinci grupta ise kadınların kendine güvenli yaklaşım becerilerinin anlamlı bir şekilde daha yüksek olduğu sonucuna varmıştır. Yine aynı durumda beden eğitimi ve spor yüksekokulu öğrencilerinin problem çözme becerilerini araştıran Türkçapar (2009) araştırmasında erkeklerin lehine anlamlı farklılık olduğu sonucuna ulaşmıştır. Kalfa (2017) çalışmasında eğitimsel doyum, sosyal duyum, rahatlama doyumu ve estetik doyumu düzeylerinin cinsiyet değişkenine göre istatistiksel olarak anlamlı bir şekilde farklılaşmadığı sonucunu bulmuş, psikolojik doyum ve fizyolojik doyumlarının ise cinsiyet değişkenine göre istatistiksel olarak anlamlı düzeyde farklılıştı̆g sonucuna varmıştır. Hem psikolojik doyum hem de fizyolojik doyum düzeylerinde erkek katıllımcilar daha yüksek doyuma sahip olmuşlardır. Ankara, Bolu ve Düzce' deki gençlik merkezi üyelerine yönelik yapılan araştırmada serbest zaman doyum düzeyleri arasında cinsiyet durumundan değerlendirildiğinde Psikolojik, Eğitim ile Rahatlama alt boyutlarında kadınların serbest zaman doyum düzeylerinin erkeklere nazaran daha yüksek çıktığı görülmüştür (Sönmezoğlu ve ark, 2014). Gökçe (2011) y1lında yapmış olduğu araştırmasında, serbest zaman doyum düzeylerini cinsiyet değişkenine göre incelemiş ve rahatlama ile fizyolojik alt boyutlarında anlamlı farklılık bulmuştur. Yetim (2014) Eskişehir'deki fitness merkezi kullanıcıları üzerine yapmış olduğu araştırmasında serbest zaman doyumunun cinsiyet değişkenine göre anlamlı farklılık bulunmadığı sonucu çıkmıştır.

Yaş değişkenine göre, PÇE toplam puan ortalamaları ve alt boyutlan incelendiğinde PÇE toplam puan ortalamalarında anlamlı bir farklılık tespit edilmemiştir ( $>0,05)$. "Düşünen, Değerlendirici ve Planlı Yaklaşım" alt boyutlanında ise anlamlı bir farklılık tespit edilmiştir $(\mathrm{p}<0,05)$. "Düşünen" alt boyutundaki anlamlı farklılık 18-21 yaş ile 26-29 yaş, 26-29 yaş işe 30 üstü yaş gruplarında olduğu ve 26-29 yaş gruplarının lehine olduğu görülmektedir. "Değerlendirici" alt boyutundaki anlamlı farklılık 22-25 yaş ile 30 yaş üstü arasında 22-25 yaş gruplarının lehine, ayrıca 26-29 yaş ile 30 yaş üstü arasında 26-29 yaş gruplarının lehine olduğu görülmüştür. "Planlı Yaklaşım" alt boyutundaki anlamlı farklılık ise 26-29 yaş ile 30 yaş üstü arasında olduğu ve 26-29 yaş gruplarının lehine olduğu görülmüş̧ür. SZDÖ toplam puan ortalamaları ve alt boyutlarında ise anlamlı bir farklılık tespit edilmemiştir ( $\mathrm{p}>0,05)$. Beden Eğitimi ve Spor Öğretmenliği bölümü öğrencilerinin, öğrenim şartlarına göre birbirine yakın yaşlarda olması problem çözme becerileri ve serbest zaman doyum düzeylerinin yaş değişkenine göre benzer olduğunu söyleyebiliriz. Yaşartürk vd. (2019) yaptıkları çalışmada yaş değisşkenine göre serbest zaman doyum düzeyleri karşılaştırıldığında anlamlı bir ilişkiye rastlanmamıştır ( $>>0.05)$. Benzer şekilde Yaşartürk (2019) üniversite öğrencileri üzerinde yaptğı araşırmada ise çalışmamı ile paralellik göstererek yaş değisskenine göre SZDÖ alt boyutları arasında anlamlı ilişki tespit etmemiştir. Fakat Öztaş (2018), yapmış olduğu çalışmasında yaş değişkenine göre sadece "estetik" alt boyutunda anlamlı ilişki bulunduğu gözlenmektedir. Diğer alt boyutlarında ve toplam puanlarında ise anlamlı bir farklılığa rastlanmadığı görülmüştür. Gökçe (2008) yapmış olduğu araştırmasında katılımcıların yaş değişkenine göre "psikolojik", "fizyolojik", "rahatlama" ve "estetik" alt boyutlarında ve serbest zaman toplam puanlarında anlamlı ilişki bulunduğu sonucu görülmüştür.

Sınıf değişkenine göre, PÇE ve SZDÖ toplam puan ortalamaları incelendiğinde istatistiksel olarak anlamlı bir farklılık tespit edilmemiştir ( $p>0,05)$. Sınıf değişkenine göre PÇE alt boyutları incelendiğinde "Değerlendirici ve Kendine Güvenli" alt boyutlarında anlamlı bir farklılık tespit edilmiştir $(p<0,05)$. PÇE alt boyutları açısından "Değerlendirici" alt boyutundaki anlamlı farklılık 2. sınıf ile 4. sınıf arasında 2. sinıfların lehine olduğu görülmüştür. "Kendine Güvenli" alt boyutundaki anlamlı farklılığın 1. ve 2. ve 2. ve 4. sınıf arasında olduğu ve bu farklılığın 4. sınıf öğrencilerinin lehine olduğu tespit edilmiştir. SZDÖ alt boyutları incelendiğinde "Rahatlama" alt boyutunda anlamlı farklılık tespit edilmiştir $(\mathrm{p}<0,05)$. SZDÖ alt boyutları açısından anlamlı farklılı̆̆ın 2. ve 3. Sınıflar arasında olduğu ve bu farklılığın 2. sinıf öğrencilerinin lehine olduğu tespit edilmiştir. Dolayısıyla 4. sınıf öğrencilerinin 2. ve 1. sınıf öğrencilerine göre okul ve yaşam tecrübelerinin fazla olması sebebiyle problem çözmedeki başarıları daha olumlu olduğu, 2. sınıf öğrencilerinin 3. sınıf öğrencilerine göre serbest zaman sürelerini daha verimli ve olumlu bir şekilde kullandığını söyleyebiliriz. Taylan (1990) yılında yapmış olduğu araştırmada 226 üniversite öğrencisinde, Problem Çözme Envanteri toplam puanlarının öğrencilerin öğrenim gördükleri programa göre farklı olduğunu; sınıf düzeyine göre ise farklılık olmadığını göstermiştir.

Gelir düzeyi değişkenine göre, PÇE ve SZDÖ toplam puan ortalamaları incelendiğinde istatistiksel olarak anlamlı bir farklılık tespit edilmemiştir ( $p>0,05)$. PÇE alt boyutları incelendiğinde anlamlı bir farklılık tespit edilmemiştir ( $>>0,05)$. SZDÖ alt boyutlanı incelendiğinde "Fiziksel" alt boyutunda anlamlı farklılık tespit edilmiştir $(\mathrm{p}<0,05)$. "Fiziksel" alt boyutundaki anlamlı farklılığın 1001-2000 TL ile 2001- 
3000 TL arasında olduğu 1001-2000 TL gruplarının lehine olduğu tespit edilmiştir. Dolayısıyla öğrencilerin gelir düzeyleri arttıkça serbest zaman doyum düzeylerinde ve serbest zaman sürelerinde olumlu bir etki oluşturacağı düşünülebilir. Lui ve Li (2018) tarafindan yapılan çalışmada ise yüksek gelir düzeyine sahip katılımcıların sosyal, estetik ve psikolojik boyutlarında serbest zaman doyum düzeylerinin daha düşük olduğu sonucuna ulaşmışlardır. Yaşartürk vd. (2019) yaptıkları çalışmalarında aile gelir düzeyi değişkenine göre serbest zaman doyum düzeyleri karşılaştırıldığında toplam ve alt boyut puanlarında anlamlı bir ilişkiye rastlanmıştır $(\mathrm{p}<0.05)$. Bu sonuçlardan hareketle beden eğitimi ve spor öğretmenlerinin gelir düzeyi arttıkça serbest zaman doyum düzeylerinde de artış olacağını söyleyebiliriz.

PÇE ve SZDÖ toplam puan ortalamaları arasındaki ilişkiyi göstermek için yapılan korelasyon analizi sonucunda istatistiksel olarak zayıf ve pozitif bir ilişki tespit edilmiştir $(p>0,05)$. Katılımcıların serbest zamanlarını olumlu ve doğru bir şekilde kullanması durumunda karşılaşacağ problemlerle başa çıkabilecekleri ve problem çözmedeki başarı düzeylerinin de olumlu şekilde artacağı söylenebilir. İnsanlar serbest zamanlarında; dinlenmek, çalısma stresinden uzaklaşmak, eğlenmek, sosyal olmak gibi hedeflerle açık ya da kapalı yerlerde, aktif ya da pasif bir durumda, istekli olarak farklı aktivitelere katılmaktadırlar. Bireyler sahip oldukları zaman dilimini bazen bireysel bazen de grup şeklinde değerlendirebilmektedirler. Son yıllarda yapılan birçok araştırmanın sonuçlarına göre ise kişilerin serbest zamanlarını daha çok pasif aktivitelere katılarak veya hiçbir aktivitede bulunmadıkları görülmüştür (Temir ve Gürbüz, 2012). Serbest zaman aktiviteleri, kişinin hayatındaki birden fazla sıkıntıdan kurtulması ile kişinin kendini geliştirmesini sağlayacak şekilde, insanların kendilerine, ilişkileri ile sosyokültürel uyumlarını pozitif yönde etkilemektedir (Axelsen, 2009; Iwasaki, 2007; Şener vd., 2007).

Sonuç olarak; katılımcıların problem çözme becerileri ve serbest zaman doyum düzeylerinin cinsiyet ve sınıf gibi değiş̧kenlere göre farklılık gösterdiğ̈i PÇE ve SZDÖ arasında bir ilişkinin olmadığı sonucuna ulaşılmıştır. Katıllımcıların serbest zaman doyum düzeylerini olumlu ve doğru bir şekilde kullandıkları zaman problem çözme becerilerinde de gelişme olacağını söyleyebiliriz.

Beden eğitimi ve spor öğretmeni adaylarının serbest zaman doyum ile problem çözme becerileri arasındaki ilişkinin incelenmesine yönelik yapılan bu çalışmanın neticesinde, literatüre katk1 sağlayacağ1 düşünülen öneriler aşağıda belirtilmiştir:

1. Beden eğitimi ve spor öğretmenliği bölümü öğrencilerinin serbest zamanlarında daha çok aktiviteler yapılması teşvik edilerek doyum düzeylerinde artıs sağlanabilir.

2. Bu araştırma farklı illerdeki beden eğitimi ve spor öğretmenliği bölümü öğrencilerine uygulanarak karşılaşıtırmalar yapılabilir.

3. Serbest zamanlarını ve problem çözme becerilerini iyi bir şekilde geçirmelerini sağlamak amacıyla okullarda serbest zamanlara ait faaliyetlerin imkânların arttırılması ve problem çözmelerinde başa çıabilmeleri sağlanabilir.

\section{Etik Beyan}

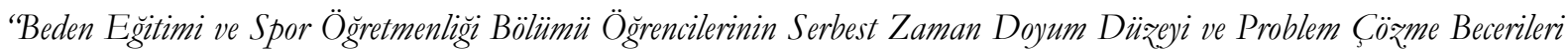
Arasındaki İliskinin İncelenmesi” başlıklı çalışmanın yazım sürecinde bilimsel, etik ve alıntı kurallarına uyulmuş; toplanan veriler üzerinde herhangi bir tahrifat yapılmamış ve bu çalışma herhangi başka bir akademik yayın ortamına değerlendirme için gönderilmemiştir.

\section{Kaynakça}

Agate, J. R., Zabriskie, R. B., Agate, S. T. ve Poff, R. (2009). Family leisure satisfaction and satisfaction with family life. Journal of Leisure Research, 2, 205-223.

Ağır, M. (2007). Üniversite ögrencilerinin bilisssel çarpıtma düzeyleri ile problem çözme becerileri ve umutsuzluk düzeyleri arasındaki ilişki (Doktora Tezi). İstanbul Üniversitesi Sosyal Bilimler Enstitüsü, İstanbul.

Avşaroğlu, S., Deniz, M. ve Kahraman, A. (1999). Teknik öğretmenlerde yaşam doyumu iş doyumu ve mesleki tükenmişlik düzeylerinin incelenmesi. Selcuk. Üniversitesi Sosyal Bilimler Enstitïsü Dergisi, 14, 115-129.

Axelsen, M. (2009). The power of leisure: I was an anorexic; I'm now a healthy triathlete. Leisure Sciences, 31(4), 330346.

Barut, Y. ve Yılmaz, M. (2000). Beden eğitimi ve spor bölümüne ve eğitim fakültesine devam eden öğrencilerin problem çözme becerilerinin çeşitli değişkenler açısından incelenmesi. Uluslararası 1. Spor Bilimleri Kongresi Bildiriler Kitabı. Ankara. 26-27.

Baumann, S. (1994). Uygulamal spor psikolojisi (Çev: C. İkizler ve A. Ö. Özcan). İstanbul: Alfa Basım Yayın Dağıtım. Beard, J. G. ve Ragheb, M. G. (1980). Measuring leisure satisfaction. Journal of Leisure Research, 12, 20-33. 
Bingham A. (1998). Cocuklarda problem çözme yeteneklerinin geliştirilmesi. (Çev: A. F. Oğuzhan). İstanbul: M.E. Basımevi.

Du Cap, M. C. (2002). The perceived impact of the Acadia advantage program on the leisure lifestyle and leisure satisfaction of the students at Acadia university (Master Thesis). Acadia University, Ottowa.

Gökçe, H. (2008). Serbest zaman doyumunun yaşam doyumu ve sosyo-demografik değişkenlerle iliş̧kisinin incelenmesi (Yüksek Lisans Tezi). Pamukkale Üniversitesi Sağlık Bilimleri Enstitüsü, Denizli.

Gökçe, H., Orhan, K. (2011). Serbest zaman doyum ölçeğinin Türkçe geçerlilik ve güvenirlik çalışması. Hacettepe Spor Bilimleri Dergisi, 22, 139-145.

Görücü, A. ve Cantav, E. (2017). A comparison of students in physical education and sports college and the students in other departments in terms of problem solving skills. Journal of Education and Training Studies, 5(5), 36-45.

Gülșen, D. (2008). Farklı lig düzeyinde oynayan futbolcularn oynadıklar mevkilere, öğrenim durumu ve spor yașlarnna göre problem çözme becerilerinin incelenmesi (Yüksek Lisans Tezi). Çukurova Üniversitesi Sağlık Bilimleri Enstitüsü, Adana.

Heppner, P. P. ve Peterson, C. (1982). The development and implication of a personal problem solving inventory. Journal of Counseling Psychology, 29(1), 66-75.

Iwasaki, Y. (2007). Leisure and quality of life in an international and multicultural context: what are major pathways linking leisure to quality of life. Social Indicators Research, 82(2), 233-264.

Kalfa, S. (2017). Spor bilimleri ve eğitim fakültesi ögrencilerinin yaşam doyumu ve serbest zaman doyumunun incelenmesi (Uşak Üniversitesi Örneği) (Yüksek Lisans Tezi). Muğla Sitk1 Koçman Üniversitesi Sosyal Bilimler Enstitüsü, Muğla.

Seigenthaler, K. (1997). Health benefits of leisure. reseach update, Parks and Recreastion, 32(1), 24-31.

Karabulut, E. O. (2009). Beden eğitimi ve spor ögretmenliüi bölïmü ögrencilerinin problem şöz̆me becerileri ile kişilik özelliklerinin baž değğskenler bakımmdan belirlenmesi ve karşlaştırlması (Ahi Evran Üniversitesi ve Gaz̧i Üniversitesi Örneği) (Doktora Tezi). Gazi Üniversitesi Sağlık Bilimleri Enstitüsü, Ankara.

Karasar, N. (2017). Bilimsel araștırma yöntemi. Ankara: Nobel Akademik Yayıncılık.

Keser, A. (2005). İş doyumu ve yaşam doyumu ilişkisi: otomotiv sektöründe bir uygulama. Çalışma ve Toplum, Ekonomi ve Hukuk Dergisi, 4, 77-96.

Köker, S. (1991). Normal ve sorunlu ergenlerin yașam doyumu düzeylerinin karşılasstırlması (Yüksek Lisans Tezi). Ankara Üniversitesi Sosyal Bilimler Enstitüsü, Ankara.

Neugarten, B. L., Havighurst, R. J. ve Tobin, S. S. (1961). The measure-ment of life satisfaction. Journal of Gerontology, 16, 134-143.

Özer, M. ve Karabulut, Ö. Ö. (2003). Yaşlilarda yaşam doyumu. Geriatri, 6(2), 72-74.

Pavot, W. ve Diener, E. (1993). The affective and cognitive context of self reported measures of subjective wellbeing. Social Indicators Research, 28, 1-20.

Pearson, Q. M. (2008). Role overload, job satisfaction, leisure satisfaction, and psychological health among employed women. Journal of Counseling and Development, 86(1), 57-63.

Şahin, N., Şahin, N. H. ve Heppner, P. P. (1993). Psychometric properties of the problem solving inventory in a group of Turkish university students. Cognative Therapy and Research, 17(4), 379-396.

Seigenthaler, K. (1997). Health benefits of leisure. Reseach Update, Parks and Recreastion, 32(1), 24-31.

Sivan, A. ve Ruskin, H. (2000). Leisure education, community development and populations with special needs. New York: CABI Publishing.

Sönmezoğlu, U., Polat, E. ve Aycan, A. (2014). Youth center members and according to some variables levels of leisure satisfaction. International Journal of Science Culture and Sport, Special Issue 1(1), 219-229.

Şener, A., Terzioğlu, R. G. ve Karabulut, E. (2007). Life satisfaction and leisure activities during men's retirement: a Turkish. Aging Ment Health, 11(1), 30-36.

Savaşır, I. ve Şahin. N. H. (1997). Bilişsel-davranış̧ı terapilerde değerlendirme: sık kullanulan ölçekler. Ankara: Türk Psikologlar Derneği Yayınları.

Taylan, S. (1990). Heppner’in problem çözme envanterinin uygulama, güvenlik ve geçerlilik çalışmalar (Yüksek Lisans Tezi). Ankara Üniversitesi Sosyal Bilimler Enstitüsü, Ankara.

Temir, Ö. ve Gürbüz, B. (2012). Rekreasyonel aktivitelere katılımın önündeki engellerin incelenmesi. 1. Rekreasyon Arastırmalar Kongresi. Antalya, 12-15 Nisan.

Türkçapar, Ü. (2009). Beden eğitimi spor yüksekokulu öğrencilerinin farklı değişkenler açısından problem çözme becerileri. Abi Euran Üniversitesi Kirşehir Ë̆titim Fakültesi Dergisi, 10(1), 129-139.

Öztaş, İ. (2018). Farklı kurumlarda çalısan memurlarn serbest zaman doyum ve mutluluke düreylerinin belirlenmesi (Kirlkekale Örneği) (Yüksek Lisans Tezi). Ağrı İbrahim Çeçen Üniversitesi Sosyal Bilimleri Enstitüsü, Ağrı.

Quintina, M. ve Vera, M. (1999). Mexican American children's ethnic identity, understanding of ethnic prejudice, and parental ethnic socialization. Hispanic Journal of Behavioral Sciences, 21(4), 387-404.

Yaşartürk, F. (2019). Analysis of the relationship between the academic self-efficacy and leisure satisfaction levels of university students. Journal of Education and Training Studies, 7(3), 106-115.

Yaşartürk, F., Akyüz, H. ve Gönülateş, S. (2019). 'The investigation of the relationship between university students' levels of life quality and leisure satisfaction. Universal Journal of Educational Research, 7(3), 739-745.

Yetim, A. (2005). Sosyoloji ve spor. İstanbul: Yaylac1k Matbaasi. 


\section{EXTENDED ABSTRACT}

Daily life difficulties problems stresses busy work situations such as the individual to renew himself, develop, enrich his life and increase the quality of life needs to devote a time to himself. People can experience problems such as depression, inefficiency in their work lives, unhappiness and increased stress when they are unable to take time out from these situations. As with all fields in the world of sports, many athletes, coaches, students, sports scientists, as well as people involved in sports have faced many problems. On the other hand, they evaluated these problems and sought different solutions.

When describing the free time, the most repeated issue in the studies is the emphasis on the time taken outside the lives of people. What is meant by this period is that it is based on the preferences of individuals as a priority, and that it creates a life satisfaction for entertainment by providing satisfaction in the person (Pearson, 2008). The satisfaction in question increases with a Social Union involving family and friends. In other words, in many studies, free time with family has positive effects on the individual's social life (Agate et al., 2009). Problem solving is expressed as the case of winning the challenges that are realized by reaching the goal. The situation shown attempts to find ways of getting rid of the tense situation by complying with the conditions or minimizing the obstacles, as well as for the organism to coexist with the internal balance. Problem solving is a skill that needs to be learned or acquired (Bingham, 1998). In a situation where the person has to solve the problem, he/she must mobilize all the resources he/she has mastered and review the information he/she has already acquired in order to obtain different ideas and tips for solving the problem. One's success in problem solving is a condition that develops due to problem solving (Ağır, 2007).

Free time contributes to the mental and physical development of individuals, reduces stress and anxiety, increases the opportunity to use personal abilities and skills, enables them to be creative, helps the development of self-expression ability, strengthens individuals ' potentials and understanding of discipline. The aim of this study is to examine the relationship between free time satisfaction and problem solving skills of physical education teacher candidates according to some demographic variables.

In this research, descriptive and relational scanning model was used. The sample of the study consisted of 536 participants (351 men and 185 women) who were selected by simple and unselected sampling method. During the research process, the researcher prepared by personal information form, Beard and Ragheb (1980) and developed by Turkish adaptation Gokce and Orhan (2011) made by "Leisure Satisfaction Scale (LSS)" by Heppner and Petersen (1982) developed and adaptation to Turkish by Sahin et al. (1993) and "Problem Solving Inventory (PSI)" was used. In the analysis of the data; the normality of the data by considering the demographic characteristics of the participants according to levels of free time in order to examine the differences between satisfaction and problem-solving skills, t-test and ANOVA; to examine the relationships between variables, Pearson's correlation test was applied.

The average age of the participants was 21.15 and the income level was 3178.85 TL per month. $34.5 \%$ of the participants were female and $65.5 \%$ were male students. $28.4 \%$ of students are 1 . class, 24.3 of 2. class, 22.8 of 3. class and 24.6 of 4 . education in the classroom. When the total score averages and sub dimensions of PSI, the total score averages and sub dimensions of LSS were examined in terms of gender variables, a statistically significant difference was found in the "avoidant" sub dimension of PSI $(p<0,05)$. A statistically significant difference in total score averages and "educational, physical and aesthetic" sub-dimensions of LSS was determined when the total score averages and sub-dimensions of LSS were examined in terms of gender variables $(p<0,05)$. When the total score averages and subdimensions of PSI were examined in terms of age variable, a statistically significant difference was found in the sub-dimensions of PSI "thinking, evaluating and planned approach" $(\mathrm{p}<0,05)$. LSS total score averages and lower dimensions were examined in terms of class variables and no significant differences were found $(p>0,05)$. A statistically significant difference was found in the "evaluative and self-confident" sub-dimensions of PSI when the total score averages and sub-dimensions of PSI were examined in terms of class variables $(p<0,05)$. A statistically significant difference in the LSS "relief" sub dimension was determined when the total score averages and sub dimensions of LSS were examined in terms of class variable $(\mathrm{p}<0,05)$. PSI total score averages and sub dimensions were examined in terms of income level variable and no significant differences were detected $(p>0,05)$. When the total score averages and sub dimensions of the LSS were examined in terms of the class variable, a statistically significant difference was found in the "physical" sub dimension of the LSS $(p<0,05)$. Pearson correlation analysis was 
performed to show the relationship between "PSI and LSS total score averages". According to the results of the analysis, no significant relationship between PSI and LSS has been determined $(p>0,05)$.

As a result, it was concluded that participants ' problem solving skills and free time satisfaction levels differed according to variables such as gender and class, and that there was no relationship between PSI and LSS. We can say that when participants use their free time satisfaction levels positively and accurately, there will also be an increase in their problem-solving skills.

It can be said that if participants use their free time positively and accurately, they will be able to deal with the problems they will encounter and their success level in problem solving will increase positively. In their free time, people are willing to participate in different activities in open or closed places, in an active or passive state, with goals such as relaxing, getting away from work stress, having fun, being social. Individuals are able to evaluate their time frame in the form of individuals or groups. According to the results of many studies conducted in recent years, it has been observed that people spend their free time participating in passive activities or not engaging in any activities (Temir, \& Gurbuz, 2012). Free time activities positively affect people's relationships and sociocultural adaptations in a way that allows them to improve themselves by getting rid of more than one problem in one's life (Axelsen, 2009; Iwasaki, 2007; Sener et al., 2007).

As a result of this study, which aims to examine the relationship between free time satisfaction and problem solving skills of physical education teacher candidates, the suggestions that are thought to contribute to the literature are as follows:

1. More activities can be done to increase the satisfaction levels of people during their free time remaining from their working life.

2. This research is applied to the students of physical education and sports teaching department in different cities and comparisons can be made.

3. In order to ensure that they spend their free time and problem solving skills in a good way, the facilities of free time activities in schools can be increased and they can be provided to cope with problem solving. 